\title{
Primates Social Impact Award 2016
}

\author{
Tetsuro Matsuzawa ${ }^{1,2,3}$
}

Published online: 10 December 2016

(C) Japan Monkey Centre and Springer Japan 2016

To celebrate the 60th anniversary of the Japan Monkey Centre (JMC) in 2016, we decided to establish a new annual prize for the paper with the highest social impact published in the journal Primates. The high social impact paper is selected by the Editor-in-Chief, Vice Editor-inChief, and Associate Editor in charge of Public Relations, based on data sources such as the Altmetric score (mentions in the media and social networking sites) and full-text downloads.

The winner of the Primates Social Impact Award 2016 is Jan A. R. A. M. van Hooff. His paper with Bas Lukkenaar, titled "Captive chimpanzee takes down a drone: tool use toward a flying object" (van Hooff and Lukkenaar 2015) got a lot of media attention, was frequently mentioned in social networks, and was highly downloaded. Their work thus contributed greatly to enhancing the reputation of our journal.

For this achievement, the lead author will receive a gift from the Japan Monkey Centre and Springer. The co-author will receive a declaration attesting to his contributions.
We are pleased to honor Jan A. R. A. M. van Hooff and Bas Lukkenaar with the first Primates Social Impact Award. After the paper was published, Prof. van Hooff kindly provided original video material with subtitles explaining the displayed behaviors, so that interested readers can view them and judge for themselves (Online Resource 1). Please join us in congratulating them and enjoy watching the video.

Tetsuro Matsuzawa

Executive Director, Japan Monkey Centre

Editor-in-Chief, Primates

\section{Reference}

van Hooff JARAM, Lukkenaar B (2015) Captive chimpanzee takes down a drone: tool use toward a flying object. Primates 56:289-292. doi:10.1007/s10329-015-0482-2
Electronic supplementary material The online version of this article (doi:10.1007/s10329-016-0592-5) contains supplementary material, which is available to authorized users.

\footnotetext{
Tetsuro Matsuzawa

matsuzawa.tetsuro.8w@kyoto-u.ac.jp

Institute of Advanced Study, Kyoto University, Kyoto, Japan

2 Primate Research Institute, Kyoto University, Inuyama, Japan

3 Japan Monkey Centre, Inuyama, Japan
} 